\title{
EFEITO DO TRATAMENTO FÍSICO ASSOCIADO À ADUBAÇÃO EM PASTAGEM DEGRADADA DE BRAQUIÁRIA, NOS TEORES DE PROTEÍNA BRUTA, FIBRA EM DETERGENTE NEUTRO E FIBRA EM DETERGENTE ÁCIDO ${ }^{1}$
}

\author{
ERIKA RAMOS PRAZERES BOMFIM ${ }^{2}$ \\ JOSÉ CARDOSO PINTO ${ }^{3}$ \\ NILSON SALVADOR ${ }^{4}$ \\ AUGUSTO RAMALHO DE MORAIS ${ }^{5}$ \\ IVO FRANCISCO DE ANDRADE ${ }^{3}$ \\ OMER CAVACANTI DE ALMEIDA ${ }^{6}$
}

\begin{abstract}
RESUMO - Na região dos cerrados brasileiros, estima-se que atualmente existam 85 milhões de hectares ocupados com pastagens, dos quais 50 milhões de hectares são de pastagens cultivadas, sobretudo com gramíneas de origem africana do gênero Brachiaria, das quais mais de $50 \%$ estão degradadas ou em processo de degradação. Conduziu-se este trabalho com o objetivo de avaliar a influência do emprego de tratamentos físicos (grade intermediária e escarificador), de doses de nitrogênio $(\mathrm{N})$ e de fósforo $(\mathrm{P})$, além das interações desses fatores na recuperação de uma pastagem degradada de braquiária (Brachiaria decumbens Stapf). Este experimento foi realizado em uma área de pastagem degradada do Departamento de Zootecnia da Universidade Federal de Lavras (UFLA), sul do Estado de Minas Gerais, Brasil. O período ex-
\end{abstract}

perimental estendeu-se de dezembro de 1998 até abril de 2000. Foi utilizado um delineamento de blocos ao acaso, em esquema de parcelas subdivididas, alocando-se os tratamentos físicos nas parcelas e as adubações de $\mathrm{N}$ e P, nas subparcelas. A adubação baseou-se nos resultados da análise de solo e constou da aplicação de $100 \mathrm{~kg} / \mathrm{ha}$ de $\mathrm{N}, 100 \mathrm{~kg} / \mathrm{ha}$ de $\mathrm{P}_{2} \mathrm{O}_{5}$ e a combinação dessas duas doses. As aplicações de $\mathrm{N}$ e $\mathrm{P}$ elevaram os teores de proteína bruta, fibra em detergente ácido, e fibra em detergente neutro apenas em resposta ao $\mathrm{P}$, no tecido vegetal de Brachiaria decumbens. Os tratamentos físicos influenciaram negativamente os teores de proteína bruta; contudo, a associação com o $\mathrm{N}$ reduziu esses efeitos negativos, elevando, porém, os teores de fibra em detergente neutro.

TERMOS PARA INDEXAÇÃO: Brachiaria decumbens, pastagem degradada, produção de MS, recuperação.

\section{EFFECT OF THE PHYSICAL TREATMENT ASSOCIATED TO FERTILIZATION IN DEGRADED PASTURES OF BRACHIARIA GRASS ON CRUDE PROTEIN, NEUTRAL DETERGENT FIBER, AND ACID DETERGENTE FIBER CONTENT}

\begin{abstract}
In the Brazilian Cerrado, it is estimated that 85 millions ha exist with pastures with 50 millions ha under cultivated pastures, especially with African grasses of the genus Brachiaria. More than $50 \%$ of this pastures are degraded or under degradational process.
\end{abstract}

The objective of this work was to evaluate the influence of physical treatments (offset disk harrow and harrowing), $\mathrm{N}$ and $\mathrm{P}$ amendments in the recovery of a degraded pasture of Brachiaria decumbens Stapf. This experiment was run in a degraded pasture of the

\footnotetext{
1. Parte da dissertação apresentada à UNIVERSIDADE FEDERAL DE LAVRAS/UFLA, Caixa Postal 37 - 37200 000 - Lavras, MG, pelo primeiro autor.

2. Mestre em Zootecnia/UFLA.

3. Professor do Departamento de Zootecnia/UFLA. Bolsista do CNPq.

4. Professor do Departamento de Engenharia/UFLA.

5. Professor do Departamento de Ciências Exatas/UFLA.

6. Mestre em Zootecnia; Zootecnista - Departamento de Zootecnia/UFRPE - Recife, PE.
} 
Animal Science Department of the Federal University of Lavras, southern area of the State of Minas Gerais, Brazil. The experiment was set from December/98 through April/00. A randomized block design was used in split plot scheme, allocating physical treatments into the main plots and the treatments with $\mathrm{N}$ and $\mathrm{P}$ into the subplots. The fertilization based on the results of the soil analysis consisted in the application of $100 \mathrm{~kg} / \mathrm{ha}$ of
$\mathrm{N}, 100 \mathrm{~kg} / \mathrm{ha}$ of $\mathrm{P}_{2} \mathrm{O}_{5}$, and the combination of these two doses. Soil addition of $\mathrm{N}$ and $\mathrm{P}$ increased the levels of crude protein, acid detergent fiber, and neutral detergent fiber as response to higher $\mathrm{P}$ in the plant. The physical treatments affected negatively crude protein content. However, the application of $\mathrm{N}$ reduced these negative effects, but increased the neutral detergent fiber levels.

INDEX TERMS: Brachiaria decumbens, degraded pasture, dry matter production, recovery.

\section{INTRODUÇÃO}

No Brasil, a produção pecuária é essencialmente extensiva e dependente das pastagens nativas e cultivadas. Apenas na região dos cerrados brasileiros, que representa uma área de mais de 200 milhões de hectares, estima-se que atualmente existam 85 milhões de hectares ocupados com pastagens. Desse total, 50 milhões de hectares são de pastagens cultivadas, sobretudo com gramíneas de origem africana do gênero Brachiaria (EUCLIDES, 1995).

Com o incremento de área das pastagens cultivadas, principalmente com a espécie Brachiaria decumbens Stapf, adaptada à região dos cerrados, de solos ácidos e de baixa fertilidade natural, houve um aumento na lotação animal, elevando-a de 0,2 a 0,3 para 0,9 a 1,0 $\mathrm{UA} / \mathrm{ha}$. O ganho de peso vivo animal cresceu, em média, de 2 a 3 vezes, em relação às pastagens nativas (MACEDO, 1999).

A B. decumbens é uma das forrageiras mais utilizadas no Brasil Central, apresentando boa adaptação a solos ácidos, uma vez que tem alta tolerância a Al e baixa exigência em $\mathrm{P}$ e Ca. Entre suas características agronômicas favoráveis, destacam-se o elevado rendimento de MS, a tolerância à baixa fertilidade dos solos e a elevada agressividade. A sua adoção resultou em um grande impulso na exploração da pecuária de corte e de leite no Brasil e ampliou consideravelmente a fronteira agrícola.

A substituição freqüente de forrageiras mais exigentes por outras menos exigentes e de pior qualidade, na formação de pastagens, quase sempre demonstra a extensão do problema da degradação de pastagens. Nesse contexto, a definição de indicadores do estado fisiológico das espécies forrageiras desejáveis torna-se relevante, especialmente quando se objetiva detectar os prenúncios da degradação antes que o processo se torne irreversível, o que permitiria estabelecer medidas de recuperação da pastagem.
Fatores como manejo inadequado e deficiências nutricionais do solo têm concorrido para reduzir a produtividade do capim-gordura (Melinis minutiflora Beauv.) nos locais onde a substituição ainda não foi processada, bem como nas pastagens de capim-braquiária (B. decumbens). O resultado, de uma maneira geral, é o surgimento de áreas descobertas, que são povoadas por invasoras de folhas largas ou por gramíneas de baixo valor nutritivo, levando à degradação das pastagens. Em situações mais graves, a redução da cobertura vegetal se acentua e as perdas do solo por erosão são facilitadas (BOTREL et al., 1988).

No Brasil, os solos das pastagens predominantemente são os Ultissolos e os Oxissolos, que geralmente apresentam sérias limitações de fertilidade. A demanda por nutrientes pelas plantas forrageiras é função do tipo de solo, níveis de adubação, espécies utilizadas e intensidade de uso das pastagens. Os teores das bases trocáveis, $\mathrm{Ca}, \mathrm{Mg}$ e $\mathrm{K}$, e os de $\mathrm{P}$ são baixos, enquanto os de Al trocável e de Mn disponível são elevados. Dessa forma, a adubação apresenta efeito marcante na pastagem, melhorando o ganho de peso vivo animal por hectare e, principalmente, a persistência das forrageiras, mesmo daquelas adaptadas à baixa fertilidade do solo.

Tem-se observado, como prática de recuperação de pastagem utilizada por pecuaristas, o emprego de equipamentos para o tratamento físico do solo, como o arado de aivecas ou arado escarificador (CASTRO e LOMBARDI NETO, 1992).

$\mathrm{O}$ arado de aivecas corta, eleva, inverte e reduz, parcial ou totalmente, as leivas, que ficam dispostas lado a lado. Já o arado de discos é menos vulnerável a essas obstruções, pois o movimento giratório dos discos faz com que eles girem sobre o solo e a vegetação, cortando-os (GADANHA JÚNIOR et al., 1991). Esses mesmos autores referem-se ao escarificador como sendo um implemento que promove a desagregação do solo de baixo para cima, atingindo profundidade maior do que a do arado de discos. Por esse motivo, o escarificador po- 
de ser utilizado para romper camadas compactadas do solo.

Objetivou-se com este trabalho avaliar a influência do emprego da grade intermediária, do escarificador com disco de corte e de doses de nitrogênio $(\mathrm{N})$, fósforo $(\mathrm{P})$ e $\mathrm{N}+\mathrm{P}$ no teor de proteína bruta $(\mathrm{PB})$, fibra em detergente neutro (FDN) e fibra em detergente ácido (FDA) na forragem de uma pastagem degradada de braquiária (Brachiaria decumbens), no sul de Minas Gerais, Brasil.

\section{MATERIAL E MÉTODOS}

O experimento foi conduzido em uma área de pastagem degradada do Departamento de Zootecnia da Universidade Federal de Lavras - UFLA, localizada na região fisiográfica do sul de Minas Gerais, geograficamente definida pelas coordenadas $21^{0} 14^{\prime} 30$ " de latitude sul e $45^{\circ} 00^{\prime} 10^{\prime}$ "de longitude oeste de Greenwich, com altitude média de 918 m (BRASIL, 1992).

A área experimental foi uma pastagem de $B$. decumbens estabelecida em 1981, tendo sido implantada como pastagem consorciada da gramínea com a leguminosa Desmodium uncinatum (Jacq.) DC. Essa espécie persistiu na área até por volta de 1994, porém, sempre com reduzida participação na composição botânica da pastagem.

A pastagem não recebeu adubações de manutenção, tendo sido gradualmente invadida por outras gramíneas e leguminosas forrageiras e plantas invasoras. Em 1998, ano de implantação deste experimento, a pastagem apresentava entre 15 a $20 \%$ de solo descoberto.

Em agosto de 1998 foi feita a análise do solo, classificado como Latossolo Vermelho Escuro, textura muito argilosa. Com essa análise, objetivou-se avaliar suas características físico-químicas para a recomendação da correção e adubação para a condução do experimento.

$\mathrm{Na}$ implantação do experimento, foi realizado um corte de uniformização da vegetação, com roçadeira costal motorizada, a $10 \mathrm{~cm}$ do solo e, em seguida, foram aplicados os tratamentos físicos $(\mathrm{M})$ e os químicos (fertilizantes).

Os tratamentos físicos corresponderam ao emprego de grade intermediária $(\mathrm{G})$, escarificador (E) e testemunha (T) (sem tratamento físico), alocados nas parcelas principais, e as aplicações de $\mathrm{N}, \mathrm{P}, \mathrm{N}+\mathrm{P}$ e testemunha (sem tratamento químico) foram efetuadas nas subparcelas, caracterizando, portanto, um fatorial $3 \times 4$ montado em blocos ao acaso, em esquema de parcelas subdivididas, com quatro repetições.
A adubação, baseada nos resultados da análise de solo, constou da aplicação de $100 \mathrm{~kg} / \mathrm{ha}$ de N, como sulfato de amônio; $100 \mathrm{~kg} / \mathrm{ha}$ de $\mathrm{P}_{2} \mathrm{O}_{5}$, como superfosfato simples; a combinação de $100 \mathrm{~kg} / \mathrm{ha}$ de $\mathrm{N}$ mais 100 $\mathrm{kg} / \mathrm{ha}$ de $\mathrm{P}_{2} \mathrm{O}_{5}$ e a testemunha. No segundo ano, essa adubação foi repetida. A calagem e a adubação potássica foram dispensadas em decorrência do baixo teor de $\mathrm{Al}$ e da alta concentração de $\mathrm{K}$ no solo.

Os quatro blocos compreendiam $324 \mathrm{~m}^{2}$ cada um, sendo a área dos carreadores de $32 \mathrm{~m}^{2}$, totalizando uma área de $1.296 \mathrm{~m}^{2}$. As três parcelas de cada bloco foram constituídas de quatro subparcelas. Cada parcela ocupava uma área de $108 \mathrm{~m}^{2}$.

Cada uma das 48 subparcelas apresentava $9 \mathrm{~m}$ de comprimento por $3 \mathrm{~m}$ de largura, com área total de 27 $\mathrm{m}^{2}$. As bordaduras das subparcelas foram constituídas de $1 \mathrm{~m}$ de cada extremidade e $0,5 \mathrm{~m}$ de cada lado, portanto, com área útil de $14 \mathrm{~m}^{2}$.

Os teores de $\mathrm{N}$ total para a estimativa da PB na MS foram determinados pelo método macro Kjedahl, segundo técnica descrita por Silva (1998). Já os teores de FDN e de FDA na MS foram determinados pelo método descrito por Van Soest et al. (1991).

Os dados obtidos de cada variável foram submetidos às análises de variância e teste de médias, processadas em microcomputador com o auxílio do pacote computacional SAEG (Sistema de Análises Estatísticas e Genéticas) (EUCLYDES, 1987).

Quando houve efeito significativo dos fatores em estudo, procedeu-se à comparação das médias dos tratamentos físicos usando-se o teste de Tukey, ao nível de $5 \%$ de probabilidade, e para os fatores $\mathrm{N}$ e $\mathrm{P}$, utilizou-se o teste F. No caso de interação significativa, procedeu-se ao seu desdobramento, estudando os níveis de um fator dentro de cada nível do outro, com posterior comparação das médias de modo idêntico ao descrito anteriormente.

\section{RESULTADOS E DISCUSSÃO}

\section{Teor de proteína bruta (PB)}

Houve efeito significativo $(\mathrm{P}<0,05)$ das interações entre $\mathrm{N}$ e tratamento físico $(\mathrm{M})$ e entre $\mathrm{P}$ e tratamento físico $(\mathrm{M})$ na concentração de $\mathrm{PB}$ na $\mathrm{MS}$ de B. decumbens, no primeiro corte. Os desdobramentos das interações podem ser observados nas Tabelas $1 \mathrm{e}$ 2. 
TABELA 1 - Teores de PB ( \%) na MS de B. decumbens em função das doses de $\mathrm{N}$ nos diferentes tratamentos físicos (M), no primeiro corte.

\begin{tabular}{cccc}
\hline \multirow{2}{*}{$\mathbf{N}$} & \multicolumn{3}{c}{$\mathbf{M}$} \\
\cline { 2 - 4 } & Gradagem & Escarificação & Testemunha \\
\hline 0 & $9,46 \mathrm{Ba}$ & $9,79 \mathrm{Aa}$ & $9,69 \mathrm{Aa}$ \\
1 & $10,77 \mathrm{Aa}$ & $9,56 \mathrm{Ab}$ & $9,20 \mathrm{Ab}$ \\
\hline
\end{tabular}

a, b na linha; A, B na coluna, diferem entre si a $5 \%$ de probabilidade (Teste de Tukey).

TABELA 2 - Teores de PB (\%) na MS de B. decumbens em função das doses de $\mathrm{P}$ nos diferentes tratamentos físicos $(\mathrm{M})$, no primeiro corte.

\begin{tabular}{cccc}
\hline \multirow{2}{*}{$\mathbf{c}$} & \multicolumn{3}{c}{$\mathbf{M}$} \\
\cline { 2 - 4 } & Gradagem & Escarificação & Testemunha \\
\hline 0 & $10,29 \mathrm{Aa}$ & $10,71 \mathrm{Aa}$ & $9,81 \mathrm{Aa}$ \\
1 & $9,94 \mathrm{Aa}$ & $8,64 \mathrm{Bb}$ & $9,08 \mathrm{Aab}$ \\
\hline
\end{tabular}

a, b na linha; A, B na coluna, diferem entre si a $5 \%$ de probabilidade (Teste de Tukey).

No segundo corte, os teores de PB na MS de $B$. decumbens foram influenciados $(\mathrm{P}<0,05)$ pela interação tripla $\mathrm{P}$ x M x N. O desdobramento da interação pode ser observado nas Tabelas 3, 4 e 5.

TABELA 3 - Teores de PB (\%) na MS de B. decumbens em função dos tratamentos físicos (M) gradagem $(\mathrm{G})$, escarificação (E) e testemunha $(\mathrm{T})$ em cada combinação de $\mathrm{N}$ e $\mathrm{P}$, no segundo corte.

\begin{tabular}{ccccc}
\hline & \multicolumn{2}{c}{$\mathbf{N = 0}$} & \multicolumn{2}{c}{$\mathbf{N}=\mathbf{1}$} \\
\cline { 2 - 5 } & $\mathbf{P = 0}$ & $\mathbf{P = 1}$ & $\mathbf{P}=\mathbf{0}$ & $\mathbf{P}=\mathbf{1}$ \\
\hline $\mathrm{G}$ & $8,79 \mathrm{a}$ & $9,93 \mathrm{a}$ & $10,61 \mathrm{a}$ & $8,87 \mathrm{a}$ \\
$\mathrm{E}$ & $8,80 \mathrm{a}$ & $9,75 \mathrm{a}$ & $10,46 \mathrm{a}$ & $8,91 \mathrm{a}$ \\
$\mathrm{T}$ & $8,88 \mathrm{a}$ & $9,65 \mathrm{a}$ & $10,46 \mathrm{a}$ & $8,96 \mathrm{a}$ \\
\hline
\end{tabular}

Valores seguidos de mesma letra, na coluna, não diferem entre si a $5 \%$ de probabilidade (Teste de Tukey).

Não houve efeito significativo dos tratamentos físicos (M) (G, E, T) em cada combinação de N e P (Tabela 3). Na ausência de P (Tabela 4), houve um acréscimo no teor de PB quando da aplicação de N; o inverso ocorreu na presença de P. Fato semelhante ocorreu com o P aplicado (Tabela 5) que, na ausência de N, proporcionou os maiores teores de $\mathrm{PB}$, enquanto na presença de N, ocorreu o contrário.

TABELA 4 - Teores de PB (\%) na MS de B. decumbens em função de N em cada combinação de P e gradagem $(\mathrm{G})$, escarificação (E) e testemunha $(\mathrm{T})$, no segundo corte.

\begin{tabular}{ccccccc}
\hline $\mathbf{N}$ & \multicolumn{3}{c}{$\mathbf{P = 0}$} & \multicolumn{3}{c}{$\mathbf{P = 1}$} \\
\cline { 2 - 7 } & $\mathbf{G}$ & $\mathbf{E}$ & $\mathbf{T}$ & $\mathbf{G}$ & $\mathbf{E}$ & $\mathbf{T}$ \\
\hline 0 & $8,76 \mathrm{~b}$ & $8,80 \mathrm{~b}$ & $8,88 \mathrm{~b}$ & $9,93 \mathrm{a}$ & $9,75 \mathrm{a}$ & $9,65 \mathrm{a}$ \\
1 & $10,65 \mathrm{a}$ & $10,46 \mathrm{a}$ & $10,46 \mathrm{a}$ & $8,87 \mathrm{~b}$ & $8,91 \mathrm{~b}$ & $8,96 \mathrm{~b}$ \\
\hline
\end{tabular}

a, b na coluna diferem entre si a $5 \%$ de probabilidade (Teste de Tukey).

TABELA 5 - Teores de PB (\%) na MS de B. decumbens em função de fósforo (P) em cada combinação de nitrogênio $(\mathrm{N})$ e gradagem $(\mathrm{G})$, escarificação $(\mathrm{E})$ e testemunha $(\mathrm{T})$, no segundo corte.

\begin{tabular}{ccccccc}
\hline \multirow{2}{*}{$\mathbf{P}$} & \multicolumn{3}{c}{$\mathbf{N = \mathbf { 0 }}$} & $\mathbf{G}$ & $\mathbf{N}=\mathbf{1}$ & \\
\cline { 2 - 7 } & $\mathbf{G}$ & $\mathbf{E}$ & $\mathbf{T}$ & $\mathbf{G}$ & $\mathbf{E}$ & $\mathbf{T}$ \\
\hline 0 & $8,79 \mathrm{~b}$ & $8,80 \mathrm{~b}$ & $8,88 \mathrm{~b}$ & $10,65 \mathrm{a}$ & $10,46 \mathrm{a}$ & $10,46 \mathrm{a}$ \\
1 & $9,93 \mathrm{a}$ & $9,75 \mathrm{a}$ & $9,65 \mathrm{a}$ & $8,87 \mathrm{~b}$ & $8,89 \mathrm{~b}$ & $8,96 \mathrm{~b}$ \\
\hline
\end{tabular}

a, b na coluna diferem entre si a $5 \%$ de probabilidade (Teste de Tukey). 
No terceiro corte, os teores de PB na MS de $B$. decumbens foram influenciados $(\mathrm{P}<0,01)$ pela interação P x N. Pelos dados da Tabela 6, verifica-se que, na ausência de $\mathrm{N}$, a aplicação de $\mathrm{P}$ elevou significativamente o teor de $\mathrm{PB}$, enquanto na presença de $\mathrm{N}$ ocorreu o contrário.

TABELA 6 - Teores de PB (\%) na MS de B. decumbens em função das doses de $\mathrm{P}$ e $\mathrm{N}$, no terceiro corte.

\begin{tabular}{ccc}
\hline \multirow{2}{*}{} & \multicolumn{2}{c}{$\mathbf{N}$} \\
\cline { 2 - 3 } & $\mathbf{0}$ & $\mathbf{1}$ \\
\hline 0 & $6,96 \mathrm{Bb}$ & $8,64 \mathrm{Aa}$ \\
1 & $7,94 \mathrm{Aa}$ & $6,99 \mathrm{Bb}$ \\
\hline
\end{tabular}

a, b na linha; A, B na coluna, diferem entre si a $5 \%$ de probabilidade (Teste de Tukey).

Assim como ocorreu no terceiro corte, no quarto e último corte os teores de PB na MS de $B$. decumbens também foram influenciados $(\mathrm{P}<0,01)$ pela interação $\mathrm{P}$ $\mathrm{x} \mathrm{N}$. Os dados do desdobramento da interação podem ser observados na Tabela 7, mostrando comportamento idêntico ao observado na Tabela 6.

TABELA 7 - Teores de PB (\%) na MS de B. decumbens em função das doses de $\mathrm{P}$ e N, no quarto corte.

\begin{tabular}{ccc}
\hline & \multicolumn{2}{c}{$\mathbf{N}$} \\
\cline { 2 - 3 } & $\mathbf{0}$ & $\mathbf{1}$ \\
\hline 0 & $6,88 \mathrm{Bb}$ & $8,31 \mathrm{Aa}$ \\
1 & $7,50 \mathrm{Aa}$ & $6,96 \mathrm{Bb}$ \\
\hline
\end{tabular}

a, b na linha; A, B na coluna, diferem entre si a $5 \%$ de probabilidade (Teste de Tukey).

No primeiro corte houve efeito do tratamento físico na concentração de $\mathrm{PB}$ na $\mathrm{MS}$ de $B$. decumbens apenas quando associado ao $\mathrm{P}$ ou ao $\mathrm{N}$. $\mathrm{O}$ tratamento com grade intermediária associado ao $\mathrm{P}$ resultou em valor superior ao observado para o tratamento com escarificador, não diferindo do testemunha (Tabela 1). Quando associado ao $\mathrm{N}$, o tratamento com grade intermediária aumentou a concentração de $\mathrm{PB}$ na MS de $B$. decumbens em relação ao escarificador e à testemunha (Tabela 2). Esses resultados parecem indicar um efeito desejável do tratamento físico com grade intermediária se associado ao $\mathrm{N}$, enquanto o tratamento com escarifi- cador não influenciou essa variável quando comparado à testemunha.

No segundo corte, o que se observou foi o efeito do $\mathrm{N}$ e do $\mathrm{N}$ associado ao $\mathrm{P}$ em interação com tratamento físico (M) (Tabelas 4 e 5). A adubação somente com $\mathrm{N}$, em qualquer um dos tratamentos físicos, aumentou a concentração de PB. Esse efeito pode ter sido influenciado pela resposta ao $\mathrm{N}$ em crescimento da forrageira, bem como ao fato de ser esse nutriente um componente indispensável na síntese de proteína. Com a associação de $\mathrm{N}$ e $\mathrm{P}$, em qualquer tratamento físico, houve uma redução da concentração de PB. Esses resultados podem estar relacionados à produção de MS de $B$. decumbens no segundo corte, em resposta à associação do $\mathrm{N}$ com o $\mathrm{P}$ que, sendo bastante expressiva, pode ter resultado em um efeito de diluição dos elementos na MS.

No terceiro e quarto cortes, os mesmos comportamentos foram observados. $\mathrm{O} \mathrm{N}$ e o $\mathrm{P}$ aplicados isoladamente aumentaram as concentrações de PB; porém, quando associados, promoveram reduções na sua concentração (Tabelas 6 e 7). Esse comportamento provavelmente está relacionado ao efeito citado no parágrafo anterior.

Os valores obtidos no presente estudo estão dentro do intervalo observado por Neves et al. (1980). Trabalhando com cultivares de braquiária, esses autores obtiveram valores médios de $\mathrm{PB}$ de 10,9 e $6,17 \%$, para cortes aos 30 e 60 dias, respectivamente, após uniformização. Segundo Corsi (1996), a adubação nitrogenada resulta em mais $\mathrm{N}$ chegando à parte aérea da planta, possibilitando seu uso na síntese protéica, elevando o teor de PB na MS da planta.

Em uma revisão sobre o valor alimentício de Brachiaria spp, Gomide e Queiroz (1994) encontraram valores inferiores de PB para a $B$. decumbens, quando comparados com os deste trabalho. Os teores de PB, entre outros fatores, são influenciados pela idade da planta, pois quanto mais avança em seu estádio de maturação, menor é a concentração de PB (Van Soest, 1994). $\mathrm{O}$ teor de N-total nos tecidos vegetais diminui progressivamente à medida que a planta vai atingindo estádios mais avançados de desenvolvimento (Corsi, 1984). Segundo Minson e Milford (1967), bovinos necessitam de uma dieta que contenha no mínimo 6\% de PB na MS, valor inferior aos deste estudo, para que a atividade dos microorganismos do rúmen seja normal.

\section{Teor de fibra em detergente neutro (FDN)}

No primeiro corte, a análise de variância revelou efeito $(\mathrm{P}<0,05)$ da interação tripla $\mathrm{P} \times \mathrm{M} \times \mathrm{N}$ nos teores de FDN na MS de B.decumbens, indicando um compor- 
tamento diferenciado dos níveis de um fator quando em presença dos níveis do outro. O desdobramento da interação pode ser observado nas Tabelas 8, 9 e 10.

TABELA 8 - Teores de FDN (\%) na MS de B. decumbens em função dos tratamentos físicos $(\mathrm{M})$ gradagem (G), escarificação (E) e testemunha (T), em cada combinação das doses de $\mathrm{N}$ e $\mathrm{P}$, no primeiro corte.

\begin{tabular}{ccccc}
\hline \multirow{2}{*}{$\mathbf{M}$} & \multicolumn{2}{c}{$\mathbf{N = 0}$} & \multicolumn{2}{c}{$\mathbf{N = 1}$} \\
\cline { 2 - 5 } & $\mathbf{P = 0}$ & $\mathbf{P}=\mathbf{1}$ & $\mathbf{P}=\mathbf{0}$ & $\mathbf{P}=\mathbf{1}$ \\
\hline $\mathrm{G}$ & $69,04 \mathrm{a}$ & $71,97 \mathrm{a}$ & $69,79 \mathrm{a}$ & $69,92 \mathrm{a}$ \\
$\mathrm{E}$ & $68,52 \mathrm{a}$ & $70,38 \mathrm{a}$ & $69,82 \mathrm{a}$ & $72,86 \mathrm{a}$ \\
$\mathrm{T}$ & $68,20 \mathrm{a}$ & $63,35 \mathrm{~b}$ & $67,08 \mathrm{a}$ & $70,30 \mathrm{a}$ \\
\hline
\end{tabular}

a, b na coluna diferem entre si a $5 \%$ de probabilidade (Teste de Tukey).

Verifica-se que a testemunha proporcionou a ocorrência dos menores teores de FDN do que a grade intermediária e o escarificador na presença de $\mathrm{P}$ e ausência de $\mathrm{N}$ (Tabelas 8 e 9). Nas demais combinações de N e P, não houve diferença significativa entre os valores de FDN na MS de $B$. decumbens dos diferentes tratamentos físicos.
$\mathrm{O}$ efeito do $\mathrm{N}$ somente foi expressivo na presença da adubação fosfatada e na testemunha (Tabela 9). Já o efeito da adubação fosfatada ocorreu na ausência de $\mathrm{N}$ e no tratamento físico testemunha (Tabela 10).

No segundo corte, apenas o tratamento com $\mathrm{P}$ influenciou $(\mathrm{P}<0,05)$ os teores de FDN na MS de B. decumbens. As parcelas que receberam a adubação fosfatada apresentaram valores de FDN superiores àquelas que não a receberam, $72,34 \%$ e $70,31 \%$, respectivamente.

Nos cortes três e quatro não houve efeito significativo dos tratamentos sobre o teor de FDN na MS de B. decumbens.

No primeiro corte, os tratamentos físicos com grade intermediária e escarificador associados ao $\mathrm{P}$ resultaram em maior percentual de FDN na MS de $B$. decumbens (Tabela 8). Da mesma forma, o $\mathrm{N}$ associado ao $\mathrm{P}$ no tratamento físico testemunha também aumentou o teor de FDN na MS de B. decumbens (Tabela 9). Como observado na variável produção de MS de $B$. decumbens, os tratamentos físicos nos primeiros cortes aparentemente influenciaram negativamente o crescimento da gramínea (Tabela 11), enquanto o $\mathrm{N}$ associado ao $\mathrm{P}$ resultou em maior produção de MS (Tabela 12) e, conseqüentemente, em função do avanço da idade no estádio vegetativo, maior deposição de parede celular nos tecidos vegetais. Esse comportamento também foi observado por Cardoso et al. (1997) em B. decumbens sob pastejo.

TABELA 9 - Teores de FDN (\%) na MS de B. decumbens em função das doses de N em cada combinação das doses de $\mathrm{P}$ com os tratamentos físicos gradagem $(\mathrm{G})$, escarificação (E) e testemunha (T), no primeiro corte.

\begin{tabular}{ccccccc}
\hline $\mathbf{N}$ & \multicolumn{3}{c}{$\mathbf{P = 0}$} & \multicolumn{3}{c}{$\mathbf{P = 1}$} \\
\cline { 2 - 7 } & $\mathbf{G}$ & $\mathbf{E}$ & $\mathbf{T}$ & $\mathbf{G}$ & $\mathbf{E}$ & $\mathbf{T}$ \\
\hline 0 & $69,04 \mathrm{a}$ & $68,52 \mathrm{a}$ & $68,20 \mathrm{a}$ & $71,97 \mathrm{a}$ & $70,38 \mathrm{a}$ & $63,35 \mathrm{~b}$ \\
1 & $69,79 \mathrm{a}$ & $69,82 \mathrm{a}$ & $67,08 \mathrm{a}$ & $69,92 \mathrm{a}$ & $72,86 \mathrm{a}$ & $70,30 \mathrm{a}$ \\
\hline
\end{tabular}

a, b na coluna diferem entre si a $5 \%$ de probabilidade (Teste de Tukey).

TABELA 10 - Teores de FDN (\%) na MS de B. decumbens em função das doses de P em cada combinação das doses de $\mathrm{N}$ com os tratamentos físicos gradagem $(\mathrm{G})$, escarificação $(\mathrm{E})$ e testemunha $(\mathrm{T})$, no primeiro corte.

\begin{tabular}{cccccccc}
\hline $\mathbf{P}$ & \multicolumn{4}{c}{$\mathbf{N = 0}$} & \multicolumn{3}{c}{$\mathbf{N = 1}$} \\
\cline { 2 - 7 } & $\mathbf{G}$ & $\mathbf{E}$ & $\mathbf{T}$ & $\mathbf{G}$ & $\mathbf{E}$ & $\mathbf{T}$ \\
\hline 0 & $69,04 \mathrm{a}$ & $68,52 \mathrm{a}$ & $68,20 \mathrm{a}$ & $69,79 \mathrm{a}$ & $69,82 \mathrm{a}$ & $67,08 \mathrm{a}$ \\
1 & $71,97 \mathrm{a}$ & $70,38 \mathrm{a}$ & $63,35 \mathrm{~b}$ & $69,92 \mathrm{a}$ & $72,86 \mathrm{a}$ & $70,30 \mathrm{a}$ \\
\hline
\end{tabular}

a, b na coluna diferem entre si a $5 \%$ de probabilidade (Teste de Tukey). 
TABELA 11 - Produção de MS (kg/ha) de B. decumbens em função de doses de $\mathrm{P}$ e dos tratamentos físicos (M) gradagem (G), escarificação (E) e testemunha (T).

\begin{tabular}{crrr}
\hline \multirow{2}{*}{$\mathbf{P}$} & \multicolumn{3}{c}{$\mathbf{M}$} \\
\cline { 2 - 4 } & \multicolumn{1}{c}{$\mathbf{E}$} & $\mathbf{T}$ \\
\hline 0 & $483,34 \mathrm{Aab}$ & $236,64 \mathrm{Bb}$ & $705,50 \mathrm{Aa}$ \\
1 & $482,37 \mathrm{Aa}$ & $506,65 \mathrm{Aa}$ & $477,48 \mathrm{Ba}$ \\
\hline
\end{tabular}

a, b na linha - efeito de tratamento físico (M) dentro de cada dose de $P(P<0,05) ; A, B$ na coluna - efeito de $P$ dentro de cada tratamento físico $(P<0,05)(T e s-$ te de Tukey).

TABELA 12 - Produção de MS (kg/ha) de B. decumbens em função de doses de $\mathrm{P}$ e $\mathrm{N}$.

\begin{tabular}{ccc}
\hline \multirow{2}{*}{$\mathbf{2}$} & \multicolumn{2}{c}{$\mathbf{~}$} \\
\cline { 2 - 3 } & $\mathbf{0}$ & $\mathbf{1}$ \\
\hline 0 & $251,30 \mathrm{Ab}$ & $292,42 \mathrm{Ba}$ \\
1 & $450,18 \mathrm{Ab}$ & $1.335,83 \mathrm{Aa}$ \\
\hline
\end{tabular}

a, b na linha - efeito de $\mathbf{N}$ dentro das doses de $\mathbf{P}$ $(\mathrm{P}<0,05) ; \mathrm{A}, \mathrm{B}$ na coluna - efeito de $\mathrm{P}$ dentro das doses de $N \quad(P<0,05)$ (Teste de Tukey).

No segundo corte, apenas a adubação com $\mathrm{P}$ influenciou a concentração de FDN na MS de $B$. decumbens. As parcelas adubadas com $\mathrm{P}$ apresentaram maiores valores de FDN quando comparadas àquelas que não o receberam. Pode-se sugerir que a adubação com $\mathrm{P}$ estimulou o crescimento da forrageira, provocando maior deposição de parede celular. No terceiro e quarto cortes, as concentrações de FDN na MS de $B$. decumbens não foram influenciadas pelos tratamentos estudados.

Os valores encontrados por Reis et al. (1990) são compatíveis com os deste trabalho. Por outro lado, Rodriguez et al. (1997) encontraram 78,30\% de FDN na parte aérea, enquanto Morais et al. (1998) registraram valores de FDN variando de $73 \%$ a $84,14 \%$ de FDN na MS de B. decumbens, superiores aos do presente estudo.

\section{Teor de fibra em detergente ácido (FDA)}

Os teores de FDA na MS de $B$. decumbens foram influenciados, no primeiro corte, tanto pelo tratamento físico $(\mathrm{M})(\mathrm{P}<0,05)$ quanto pelo $\mathrm{P}(\mathrm{P}<0,05)$.

As parcelas que receberam o tratamento físico com grade intermediária (G) apresentaram valores de
FDA de $39,05 \%$, superiores $(\mathrm{P}<0,05)$ ao tratamento testemunha $(\mathrm{T}), 37,03 \%$. Os teores de FDA das parcelas que receberam o tratamento com escarificador $(\mathrm{E})(37,91 \%)$ não diferiram $(\mathrm{P}>0,05)$ daqueles da grade intermediária $(G)$ e da testemunha $(T)$.

Não houve efeito significativo $(\mathrm{P}>0,05)$ dos tratamentos estudados nos teores de FDA na MS de $B$. decumbens nos cortes dois e três.

A análise de variância dos dados relativos ao quarto corte revelou efeito significativo $(\mathrm{P}<0,05)$ do $\mathrm{P}$ nos teores de FDA na MS de $B$. decumbens. As parcelas que receberam a adubação fosfatada apresentaram valores de $47,19 \%$, superiores aos $43,52 \%$ das parcelas que não a receberam.

Os resultados mais consistentes dos efeitos dos tratamentos estudados nos teores de FDA na MS de $B$. decumbens parecem estar relacionados à adubação com P. De maneira semelhante ao observado para a variável FDN, aparentemente o P estimulou a deposição de parede celular na forragem da gramínea, elevando a concentração de FDA. Esse fato foi observado no primeiro e último cortes.

Nunes et al. (1984), avaliando os teores de PB e FDA em plantas de B. brizantha, encontraram teores de FDA na MS das folhas de 33,0\% (estação seca) e 34,0\% (estação chuvosa). Os valores de FDA deste trabalho concordam com os encontrados por Gomes Júnior (2000) que, avaliando o desempenho de novilhos em recria suplementados em pastagem de $B$. decumbens, observou valores de FDA que variaram de 41,66 a $48,23 \%$. Benedetti et al. (1995), trabalhando com avaliação de três espécies forrageiras tropicais, também observaram valores médios de $41,31 \%$ de FDA na MS de B. decumbens.

\section{CONCLUSÕES}

$\mathrm{A}$ adubação com $\mathrm{N}$ elevou os teores de $\mathrm{PB}$ e FDA no tecido vegetal de B. decumbens.

$A$ aplicação de $\mathrm{P}$ resultou em maiores concentrações de PB, FDN e FDA na MS de B. decumbens.

Os tratamentos físicos influenciaram negativamente os teores de $\mathrm{PB}$; contudo, a associação com o $\mathrm{N}$ reduziu esses efeitos negativos, elevando, porém, os teores de FDN na MS de B. decumbens.

\section{REFERÊNCIAS BIBLIOGRÁFICAS}

BENEDETTI, E.; RODRIGUEZ, N. M.; GONÇALVES, L. C. Avaliação de forrageiras tropicais: Compor- 
tamento nutricional de três espécies de gramíneas no cerrado do Triângulo Mineiro. In: REUNIÃO ANUAL DA SOCIEDADE BRASILEIRA DE ZOOTECNIA, 31., 1995, Brasília. Anais... Brasília: SBZ, 1995. p. 268.

BOTREL, M. A.; CRUZ FILHO, A. B.; CARVALHO, M. M. Recomendações para a formação e manejo de pastagens na Zona da Mata de Minas. Informe Agropecuário, Belo Horizonte, v. 13, n. 153/154, p. 12-22, 1988.

BRASIL. Ministério da Agricultura. Normais Climatológicas: 1961-1990. Brasília, 1992. 84 p.

CARDOSO, E. G.; SILVA, J. M. da; EUCLIDES, V. P. B. Proteína bruta e fibra em detergente neutro em $B$. decumbens sob pastejo. In: REUNIÃO ANUAL DA SOCIEDADE BRASILEIRA DE ZOOTECNIA, 33., 1997, Juiz de Fora. Anais... Juiz de Fora: SBZ, 1997. p. 261-263.

CASTRO, O. M.; LOMBARDI NETO, F. Manejo e conservação de solos em citros. Laranja, Cordeirópolis, v. 13, p. 275-305, 1992.

CORSI, M. Adubação nitrogenada das pastagens. In: SIMPÓSIO SOBRE MANEJO DA PASTAGEM, 10., 1996, Piracicaba. Anais... Piracicaba: FEALQ, 1996. p. 121-153.

CORSI, M. Effects of nitrogen rates and harvesting intervals on dry matter production, tillering and quality of the tropical grass Panicum maximum Jacq. 1984. 125 f. Thesis (PhD) - Ohio State University, Ohio, 1984.

EUCLYDES, R. F. Sistema para análises estatísticas e genéticas: guia do usuário resumido. Viçosa: Fundação Arthur Bernardes, 1987. 82 p.

EUCLIDES, V. P. B. Algumas considerações sobre o manejo de pastagens. Campo Grande: EMBRAPA/CNPGC, 1995. 31 p. (Documentos, 57).

GADANHA JUNIOR, C. D.; MOLIN, J. J. P.; COELHO, J. L. D.; YAHAN, C. H.; TOMIMORI, S. M. A. W. Máquinas e implementos agrícolas do Brasil. São Paulo: Instituto de Pesquisas Tecnológicas do Estado de São Paulo, 1991. 468 p.

GOMES JÚNIOR, P. Composição químicobromatológica da Brachiaria decumbens e desempenho de novilhos em recria suplementados durante a época seca. 2000. 51 p. Dissertação (Mestrado em Zootecnia) - Universidade Federal de Lavras, Lavras, 2000.

GOMIDE, J. A.; QUEIROZ, D. S. Valor alimentício das Brachiarias. In: SIMPÓSIO SOBRE MANEJO DA PASTAGEM , 11., 1994, Piracicaba. Anais... Piracicaba: FEALQ, 1994. p. 223-248.

MACEDO, M. C. M. Degradação de pastagens, conceitos e métodos de recuperação. In: SUSTENTABILIDADE DA PECUÁRIA DE LEITE NO BRASIL, 1999, Juiz de Fora. Anais... Juiz de Fora: EMBRAPA/CNPGL, 1999. p. 137-150.

MINSON, D. J.; MILFORD, R. The voluntary intake and digestibity of diets containing different proportions of legume and mature pangola grass (Digitaria decumbens). Australian Journal of Experimental Agriculture and Animal Husbandry, Melbourne, v. 7, n. 29, p. 546-551, Dec. 1967.

MORAIS, M. G.; BORGES, A. L. C. C.; GONÇALVES, H. O. S. L.; BORGES, I.; RODRIGUEZ, N. M. Variação da parede celular da Brachiaria decumbens: fibra detergente neutro, fibra detergente ácido, celulose e lignina. IN: REUNIÃO ANUAL DA SOCIEDADE BRASILEIRA DE ZOOTECNIA, 35., 1998, Botucatu. Anais... Botucatu: Gnosis, 1998. 1 CD-ROM.

NEVES, M. P. H.; KASS, M. L.; SERRÃO, E. A. S. Introdução e avaliação preliminar de gramíneas do gênero Brachiaria na região de Belém, Pará. In: CONGRESSO BRASILEIRO DE ZOOTECNIA, 1., 1980, Fortaleza. Anais... Fortaleza: UFC, 1980. p. 406-407.

NUNES, S. F.; BOOK, A.; PENTEADO, M. I. Brachiaria brizantha $c v$. Marandu. Campo Grande: EMBRAPA/CNPGC, 1984. 31 p. (Documentos, 21).

REIS, R. A.; GARCIA, R.; QUEIROZ, A. C.; SILVA, D. J.; FERREIRA, J. Q. Efeito da aplicação de amônia anidra sobre a composição química e digestibilidade in vitro dos fenos de três gramíneas forrageiras de clima tropical. Revista da Sociedade Brasileira de Zootecnia, Viçosa, v. 19, n. 3, p. 219-228, 1990.

RODRIGUEZ, N. M.; BORGES, A. L. C. C.; FILGUEIRAS, E. P.; ESCUDER, C. J.; GONÇALVES, L. C. Efeito de quatro períodos de vedação sobre a produção de Brachiaria decumbens Stapf. 2: fibra detergente neutro, fibra detergente ácido, celulose, lignina e digestibilidade in vitro da matéria seca. Arquivo Brasi- 
leiro de Medicina Veterinária e Zootecnia, Belo Horizonte, v. 49, n. 5, p. 603-616, 1997.

SILVA, D. J. Análise de alimentos: métodos químicos e biológicos. Viçosa: UFV, 1998. 165 p.

VAN SOEST, P. J. Nutritional ecology of the ruminant. 2. ed. New York: Cornell University, 1994. 476 p.
VAN SOEST, P. J.; ROBERTSON, J. B.; LEWIS, B. A. Methods for determinations of dietary neutral detergent fiber, and nonstarch polysaccharides in animal nutrition. Journal of Animal Science, Champaign, v. 74, n. 10, p. 3583-3597, Oct. 1991. 